\title{
Mainstreaming Sustainable Decision-making for Ecosystems: Integrating Ecological and Socio-economic Targets within a Decision Support System
}

\author{
Rute Pinto • Maria da Conceição Cunha • \\ Catarina Roseta-Palma • João Carlos Marques
}

Received: 15 November 2013 / Accepted: 11 December 2013 /Published online: 29 April 2014

(C) Springer International Publishing Switzerland 2014

\begin{abstract}
Ecosystem sustainable management, and the underlying decision-making process, generally requires the analysis of ecological, social and economic information, integrating both value judgements and policy goals. Since this process can be regarded as complex and tricky, natural resource management requires a well-structured and transparent decision-making process. In this regard, it is necessary to search for and implement sets of measures which can effectively solve emerging problems. Based on the assumption that decisions concerning the management of watersheds may imply trade-offs between their different functions, the intent was to test if software tools, such as MULINO, could be used to enhance multi-level governance of ecosystems. To achieve this, the DPSIR and MCA were incorporated, to analyze and quantify the explicit trade-offs between several types of services provided by estuarine ecosystems and stakeholder objectives. The Mondego Estuary (Portugal) was used as case study. This system is under constant pressure, from both natural and anthropogenic drivers. Urban expansion and tourism were identified as having a strong impact on system development, while agriculture, although declining, had a determinant role in the system's status. The study evaluated potential alternatives focusing on the water quality improvement goals that could be designed for the system. The MCA ranked several alternatives and pinpointed as the best option the alternative that combines buffer zones, eco-tourism enhancement, wastewater treatment plant development, the Murraceira trademark and bivalves bio-control. This analysis
\end{abstract}

R. Pinto $(\bowtie) \cdot$ J. C. Marques

IMAR - Institute of Marine Research, Department of Life Sciences, Largo Marquês de Pombal, 3004-517 Coimbra, Portugal

e-mail: rutepinto@ci.uc.pt

R. Pinto

CENSE - Center for Environmental and Sustainability Research, FFCT/UNL, Campus da Caparica, 2829-516 Caparica, Portugal

M. da Conceição Cunha

IMAR - Institute of Marine Research, Department of Civil Engineering, Universidade de Coimbra, Pólo II, 3030-788 Coimbra, Portugal

C. Roseta-Palma

ISCTE - Instituto Universitário de Lisboa, Dep. Economia and BRU - IUL, Av. Forças Armadas, 1649-026 Lisboa, Portugal 
allowed a simplification of several management objectives; nonetheless, further tests are still required to understand the real connection between these outcomes and decision-makers.

Keywords Water quality improvements - WFD · DPSIR framework · Ecosystem services · MULINO-MCA · Decision-support system

\section{Introduction}

Increasing human population, economic growth and global consumption patterns place increasing pressure on environmental systems (Vitousek et al. 1997), hence affecting the provisioning of ecosystem goods and services valued by society (e.g., Seppelt et al. 2011).

To contradict these trends in Portugal, as worldwide, policies regarding water quality improvement have relied on regulatory approaches (Morris 2007), often directed towards the setting of targets for ecological water quality, conservation of species and their habitats. An example is the EU Water Framework Directive (WFD; EC 2000). The resulting achievement of the good ecological status (GES) in European water bodies is expected to generate substantial direct and indirect benefits (e.g., Brouwer 2008). However, a concurrent problem facing environmental agencies is how to efficiently distribute funds to enhance natural capital (e.g., Hajkowicz et al. 2009). According to Mysiak et al. (2002) 'Environmental decisions require a spatial analysis of the impacts resulting from possible options in order to guarantee spatially balanced sustainable development . Hence, in the processes of sustainability assessments and/or environmental planning of ecosystems, it becomes fundamental to ensure the accurate interweaving of disciplinary approaches. Several approaches have been considered for this task, like ecological indicators development (e.g., Salas et al. 2006), geographic information systems (GIS; Mysiak et al. 2002), or even the ecosystem services concept (e.g., Seppelt et al. 2011). The WFD adopts the DPSIR (Drivers-Pressures-Status-Impacts-Responses) approach as a possible analytical framework for determining pressures and impacts (Borja et al. 2006; Pinto et al. 2013a) and to achieve sustainable water resources management. The use of several approaches is always advised to achieve a better evaluation of ecosystem integrity combined with current human demands, perceived as key for the sustainable development of ecosystems.

Sustainable development is a complex issue, involving strongly interconnected ecological, social, and economic aspects of an ecosystem, now and in the future (de Jonge et al. 2012). In fact, according to Kiker et al. (2005), 'Decision-making in environmental projects can be complex and seemingly intractable, principally because of the inherent trade-offs between socio-political, environmental, ecological, and economic factors'. Decisions affect different stakeholder groups in different ways, leading to inevitable tradeoffs between them and between present and future generations. Decision-making involving such complex systems requires a logically well-structured process.

Multi-criteria analyses (MCA) have been recommended as useful tools to ensure an integrated management of an ecosystem, allowing the incorporation of different sets of data (e.g., Villa et al. 2002; Pavlikakis and Tsihrintzis 2003; de Jonge et al. 2012). MCA is a stepwise process that allows the comparing of decision alternatives with multiple and often complex impacts (Hermann et al. 2007). The information is often structured using a software tool, which aims to record proposed alternatives, while measuring and assessing their impacts (Hermann et al. 2007). 
In this work, directed at mainstream decision-support tools to address the sustainable management of ecosystems, the MCA-MULINO software (Giupponi and Cogan 2000; Mysiak et al. 2005; Giupponi 2007) was evaluated (http://siti.feem.it/mulino/mulino.htm). The software incorporates integrated analysis modelling (IAM), MCA, and the DPSIR framework of environmental cause-effect relationships (La Jeunesse et al. 2003). The MULINO software was developed within the European water policy context, more specifically to answer WFD requirements. This software has been implemented in several European River Basins, like the Bahlui river catchment in Romania, the Caia river catchment in Portugal, the Yare river catchment in the UK, the Nethen catchment in Belgium, or even the Vela river catchment in Italy (Giupponi and Cogan 2000). In this case study, the MULINO tool was chosen mainly because it allows designing and implementing an operational decision support system for the management of water resources that is based on hydrologic modelling, multidisciplinary (qualitative and quantitative) indicators and a multi-criteria evaluation procedure. Moreover, the MULINO tool relies on the DPSIR framework, which was the chosen approach to evaluate the main drivers and pressures acting on the Mondego Estuary case-study. However, some criticisms have been pointed to the DPSIR framework, such as the absence of an explicit stakeholder role in the process, since stakeholders may participate but the engagement cannot be described satisfactorily (e.g., Bruins and Heberling 2005), especially where linear and direct links are difficult to establish (Pinto et al. 2013a). When integrated into the MULINO tool, however, DPSIR presents an evolution from a static framework to a dynamic multi-disciplinary modelling setting (Linkov et al. 2006).

The overall objective of the MULINO application to the Mondego Estuary case-study was to ensure multi-disciplinary integration of information, to facilitate decision-making processes between multi-level background governance.

Aiming at a sustainable management of the system, the research allowed:

- to assess how the DPSIR framework could be enhanced to facilitate decision-making processes;

- to enhance multi-level governance of natural resources, based on the integration of public preferences into the MCA; and

- $\quad$ to test how MULINO worked on water quality improvement scenarios.

\section{Methodology}

\subsection{Case-study Description}

The Mondego Estuary is located on the northwestern coast of Portugal (Fig. 1). The estuary is divided by the Murraceira Island, in its terminal part, into two arms (North and South Arms). These two arms present very different characteristics and are considered as two sub-systems, where the North Arm has been judged to possess impoverished benthic communities relative to the South Arm, mainly due to higher sediment instability (Marques et al. 1993). The North Arm is deeper than the South Arm (5-10 m during high tide), presents stronger daily salinity changes (the freshwater flows basically through this arm), and the bottom sediments consist mainly of medium to coarse sand (Marques et al. 1993). This estuarine branch constitutes the principal navigation channel, supporting the harbour and city of Figueira da Foz, and is subject to regular dredging activities. The South Arm is shallower (2-4 m during 


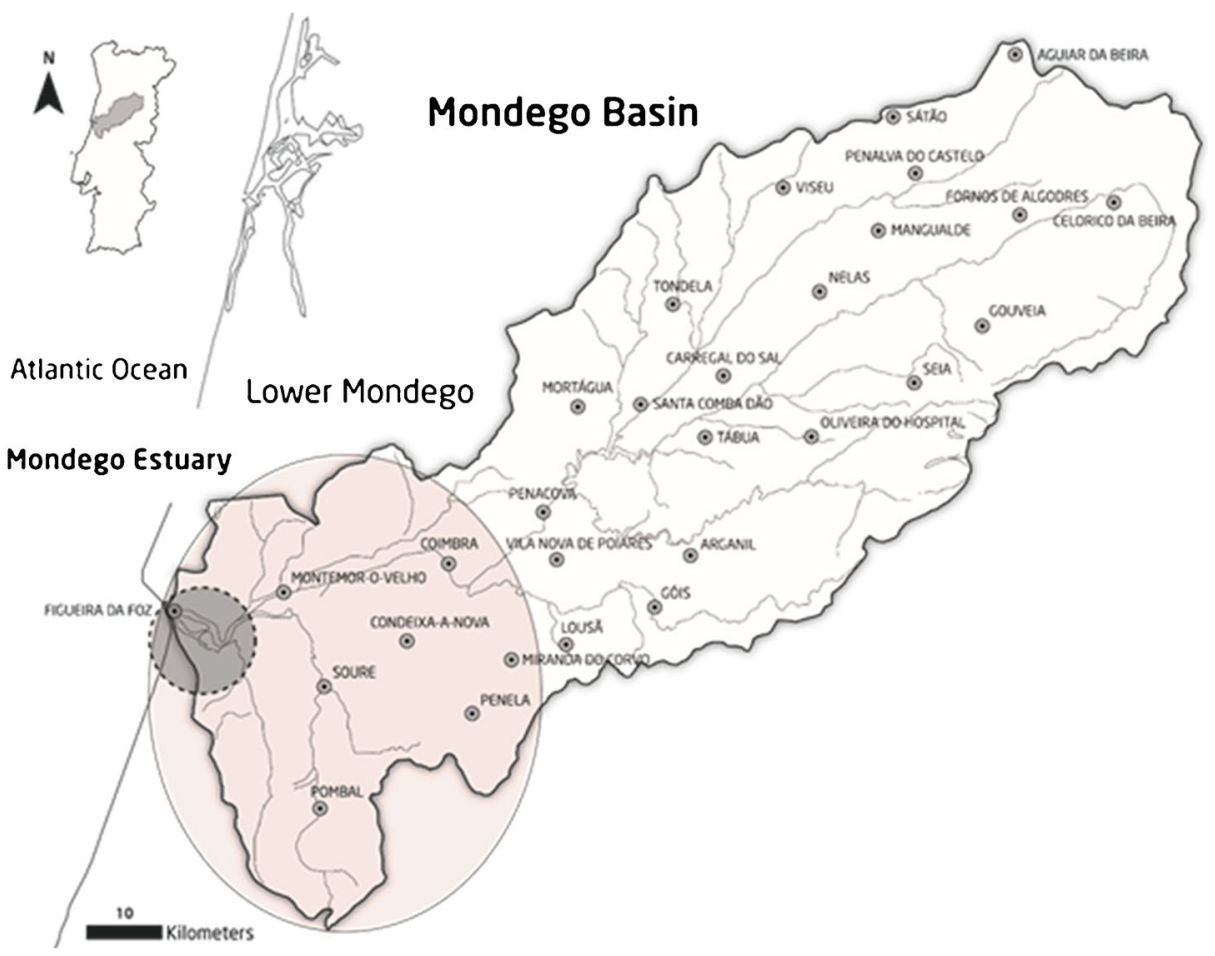

Fig. 1 The Mondego Estuary study-site location

high tide) and consists of mostly sandy to muddy channel beds. Up to recently (2006), the upstream connection to the main river course was almost closed by sediment deposition. This constraint forced the water circulation to be mainly dependent on tidal penetration and the freshwater inflow of a tributary, Pranto River, controlled by a sluice (Flindt et al. 1997; Marques et al. 2003). The combined effect of an increased water residence time (circa 9 days) and high nutrient concentrations lead to the occurrence of seasonal blooms of Ulva spp. and a concomitant severe reduction of the area occupied by Zostera noltii beds (Martins et al. 2001), previously the richest habitat in terms of productivity and biodiversity (Marques et al. 1993). Moreover, the entire estuary is characterized as being under permanent anthropogenic pressure, e.g., dredging activities, nutrients runoff (Marques et al. 2003; Pinto et al. 2010). Firstly, the surrounding area supports many economic activities, which vary from extractive activities (e.g., agriculture and salt production) to on-site activities (e.g., leisure and tourism). Patently, this panoply of uses influences the ecological condition and performance of the estuarine communities (Pinto et al. 2010; 2013b; 2014). In addition, the system also provides a wide range of ecosystem goods, such as the capture of bivalves and fish.

This research presents a case study, with main emphasis given to estuarine water quality improvements, as a crucial ecosystem service provided by the Mondego Estuary system; it focusses on the main pressures driving the ecosystem status and the impacts on human wellbeing, including estimates of changes in ecosystem services provision under different response scenarios (e.g., possible measures to be implemented). 


\subsection{The MCA-MULINO software}

This MCA tool relies on the assumption that stakeholders identified water quality improvement as a key issue for local and even national development. Scientific and technical expertise (e.g., in the valuation of ecosystem services) were used to complement stakeholder inputs. Alternatives were evaluated according to how well they achieve the proposed objectives.

The MULINO decision support tool, handling both quantitative and qualitative data, comprises three phases of analysis (Giupponi and Cogan 2000):

- The 'Conceptual Phase': where the user investigates and identifies causal links between human activities (D), the pressures they exert (P), and the state of the environment (S). This phase produces a formal description of activities and issues relevant to catchment management and makes relationships between these factors explicit in the form of 'DPS chains'. It is in this first phase that mathematical modelling and local network analyses can be used to explore the problem in different ways;

- The 'Design Phase': where the identification of alternative options for possible responses, such as specific water management projects, is undertaken. Using MULINO, the user constructs a matrix with $n$ rows of decisional indicators, or criteria, and $m$ columns of options. This formalises the structure of the 'analysis matrix'. The analysis matrix cells can be filled with values derived from indicator monitoring, model outputs and/or expert judgements. The pairwise comparison approach (e.g., Malczewski 1999) is adopted to structure the inclusion of expert opinions when quantitative data are not available or when subjective choices have to be made, such as for the weighting of criteria. Value functions and normalisation procedures allow the user to produce an 'evaluation matrix' which can be used to compare the expected impacts (I) of the alternative decisional options. A hierarchical weighting procedure is included to facilitate the elicitation of the decision maker's preferences and to support the interface between them and their technical staff;

- The 'Decision Phase': where the user elaborates a concise presentation of decisional criteria, using alternative decision rules: simple additive weighting (SAW); ordered weighted averages (OWA); a technique for order preference by similarity to ideal solution (TOPSIS); or ELECTRE. In this case study only the SAW and TOPSIS methods were applied and tested. The application of any of these methods to solve the decision problem will elicit the user's preferences with reference to the alternative options to arrive at a response (R). The results can be further investigated and re-assessed by means of sensitivity analysis enhancing the evaluator' awareness of the effects of subjective judgements such as criteria selection, weighting, and value function on the final result.

\subsubsection{Alternatives, Criteria, and Water Quality Improvement}

Taking into account the work developed concerning ecosystem service evaluation and the programmes of measures included in the River Basin Management Plans (RBMP), a MCA framework was set up.

The alternatives represent the different choices of action available to the decision-maker. The set of alternatives is assumed to be finite, and can then be screened, prioritized and eventually ranked. In this case-study the proposed alternative measures were developed relying on the River Basin Plans (RBMP) developed for the Mondego catchment area and based on expert knowledge of the system functioning. From this integration, a list of 8 measures/options were considered: 
1) Buffer zone creation: construction of a vegetated buffer zone to reduce water pollution coming from agricultural fields, through the retention of nutrients and pesticides in these macrophytes areas, thus avoiding their introduction in the water cycle.

2) Changes in agricultural practices, aiming to improve water use efficiency and control of nutrients: test the effect that changing agriculture practices may have on water resources, through not only a more efficient use of irrigation water, but also a focus on 'quality' rather than 'quantity' production.

3) Increasing of the connectivity between the two estuarine arms: guarantee the accurate connection between the estuarine South Arm and the main river course, ensuring efficient water circulation in this sub-system (in order to reduce the eutrophication symptoms that are already felt). This was in fact one of the main proposed measures in the RBMP for this system.

4) Creation of an ecotourism center: promotion of the implementation of an ecotourism centre in the Murraceira Island, with bird-watching and pedestrian activities.

5) Construction of wastewater treatment plants: to measure the impacts that wastewater treatment plants, located upstream of the estuarine area, might have to determine the system' good status.

6) Construction of wastewater treatment plants with associated macrophytes buffer zones: This measure is an extension of the previous one; buffer zones are created around the point sources of the wastewater treatment effluent points, in order to reduce the nutrients released to the water course.

7) Murraceira trade-mark: Promotion of a local brand based on the production of local assets, such as bivalves, aquaculture fish or salt, as 'image-product' of the good quality of the system, relying on sustainable practices. This would imply marketing campaigns and divulgation of the products.

8) Pollution retention on biological resources: potential capacity of using the estuarine natural biological resources, such as bivalves, as possible nutrient storage.

Here only the 8 basic alternatives are presented, however, additional alternatives, resulting from the combination of these measures, were taken into account, performing a total of 247 possible alternatives. Based on the problem and objectives of the study, the measures or combinations of measures (all possible alternatives) to solve the problem are suggested. Afterwards, scores for these measures with respect to different criteria are assessed (here given by Investment, Performance, and Risk criteria). Criteria represent the different dimensions from which the alternatives can be viewed, being at the basis for a decision that can be measured and evaluated, i.e., a standard of judgement to test the desirability of the options (Mysiak et al. 2002). In this analysis, three types of criteria were considered:

- Investment: This criterion considers the initial investment necessary to implement each of the considered measures. In order to achieve this, the NPV (Net Present Value; Ross et al. 2013) was used for each measure (using a $3 \%$ discount rate), allowing the comparison of the cost-effectiveness between measures. The year 2027 was used as reference, as in the RBMP, since it is the year that the ARH Centro, Portugal, predicts that the basin will achieve the Good Ecological Status;

- Performance (social, ecological and economic): Each measure's performance is evaluated in a semi-qualitative way, combining the (social, economic and ecological) importance of the services and their status evolution through time (final scale given by 'Low', 'Medium' and 'High' scores). It translates the performances of options for every decisional criterion into value scores, which represent the degree to which a decision objective is matched; 
- Risk exposure (social, ecological and economic): This criterion is evaluated using the 'Vulnerability Assessment Method' (Stratford et al. 2011).

The modelling of criteria weights is proposed to be based on population surveys and expert judgments. By including cost, effectiveness, and risk criteria in the analysis, the MCAMULINO tool allows us to have a broader view of the proposed measures than the usual cost-effectiveness calculations that are part of the economic analysis required by the WFD.

\subsubsection{Weights and Analysis}

In this study, we evaluated the results achieved through the application of two methods available in MULINO regarding decision-making processes: SAW and TOPSIS. A short explanation of both approaches is needed to understand the differences in the results. The intent was to aggregate partial preferences describing individual criteria in a global preference, and then rank the options (Mysiak et al. 2005):

- SAW is the most popular decision method mostly due to its simplicity. It assumes additive aggregation of decision outcomes, which is controlled by weights expressing the importance of criteria. This method is a simple additive weighting, where it uses the additive aggregation of the criteria outcomes, given by (Mysiak et al. 2005):

$$
\Phi_{S A W}\left(a_{i}\right)=\sum_{j=1}^{n} w_{j} \times u_{i j} w_{j} \text { criterion weights }
$$

- TOPSIS orders a set of options on the basis of their separation from the ideal solutions. The option that is closest to the ideal positive solution and furthest from the negative (anti-)ideal solution is the best one (Rodrigues 2002). The measurement of separation requires distance metrics, usually Euclidean distances. The ideal point methods order a set of options on the basis of their separation from the ideal solution (Mysiak et al. 2005):

$$
s_{i}=\left[\sum_{j=1}^{n} w_{j}^{p}\left(u_{i j}-u_{+j}\right)^{p}\right]^{1 / p}
$$

$\mathrm{S}_{\mathrm{i}+} \quad$ separation of the ith option from the ideal point

$\mathrm{w}_{\mathrm{j}} \quad$ weight assigned to the criterion $\mathrm{j}$

$\mathrm{u}_{+\mathrm{j}} \quad$ ideal value for the $\mathrm{j}$ th criterion

$\mathrm{p} \quad$ power parameter ranking from 1 to $\infty$

This equation shows the distance metric, where the parameter $p$ allows defining the distance. According to Mysiak et al. (2005), for ' $\mathrm{p}=1$, the rectangular distance is achieved while for $p=2$ the Euclidian distance is calculated'. Therefore, the ideal solution represents an (not achievable and thus only hypothetical) option that consists in the most desirable level of each criterion across the options under consideration. Similarly, for the ideal negative solution, the best option may be defined/characterised by the maximum distance from it (Mysiak et al. 2005): 


$$
s_{i-}=\left[\sum_{j=1}^{n} w_{j}^{p}\left(u_{i j}-u_{-j}\right)^{p}\right]^{1 / p}
$$

$\mathrm{S}_{\mathrm{i}-} \quad$ separation of the ith option from the negative ideal point

$\mathrm{u}_{-\mathrm{j}} \quad$ negative ideal value for the $\mathrm{j}$ th criterion

\section{Results and Discussion}

The MULINO software intents to provide a DSS that supports decision-making in the integrated management of water resources at the catchment scale. In the Mondego Estuary, the good knowledge regarding the system structure and functioning allowed the work to take advantage of the MULINO outputs to: (1) deal with integrated management alternatives; (2) help the implementation of the participatory approach, as well as the economic requirements within the WFD context, and (3) contribute to a more sustainable use of water-related ecosystems within a catchment area.

The ranking order of the alternatives are presented and discussed for the Mondego Estuary. Table 1 presents the investments considered for the several alternatives of measures to be implemented.

Considering the performance and risk reduction (social, ecological and economic) values, alternatives (the eight basic alternatives or their combination) were ranked, using the MULINO software described previously and considering two techniques: SAW and TOPSIS (Table 2a). This approach provided the ranking of the best alternatives to be considered. From this analysis, it is possible to see that, from the 247 possible combination of alternatives ('comb' in Table 2), the combinations considering alternatives 4 (eco-tourism enhancement), 5 (wastewater treatment plant development) and 8 (bivalves bio-control) were ranked among the most effective for the water quality improvement issues.

In fact, the combination of alternatives 1 (buffer zones), 4 (eco-tourism enhancement), 5 (wastewater treatment plants development), 7 (Murraceira trade-mark) and 8 (bivalves biocontrol) was ranked as the most attractive option by the SAW method for the water quality enhancement (Table 2b). Considering the TOPSIS method, the most efficient solution would be the combination of all considered alternatives.

Although this analysis relied on the weights input from stakeholders regarding water quality improvements, it can, however, support social interaction between stakeholders within the context of dialogue if the chosen weights for the criteria reflect a consensus between

Table 1 Total investments considered for the several alternatives, from 2012 to 2027. Alternatives: 1buffer zones; 2-'green agriculture'; 3-connectivity improvement; 4-ecotourism enhancement; 5-wastewater treatment plants development; 6wastewater treatment plants development with associated macrophytes; 7-Murraceira trade-mark; 8bivalves bio-control

\begin{tabular}{ll}
\hline Alternative considered & Total Investment value $\left[10^{3} €\right]$ \\
\hline 1 & 4446.03 \\
2 & 54403.69 \\
3 & 38340.36 \\
4 & 1020.91 \\
5 & 457.68 \\
6 & 20615.45 \\
7 & 11663.83 \\
8 & 5281.06
\end{tabular}




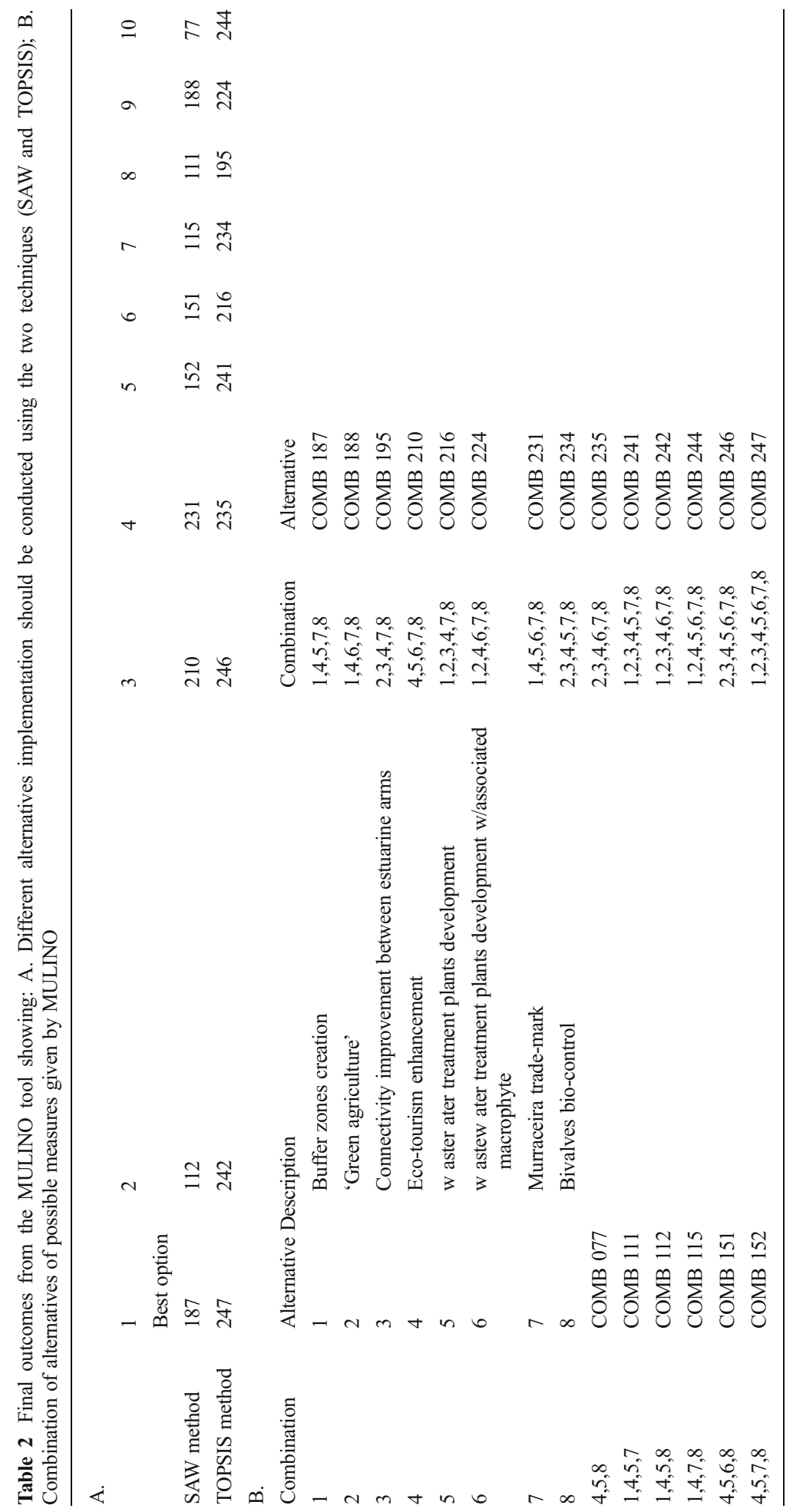


stakeholders (La Jeunesse et al. 2003; Pavlikakis and Tsihrintzis 2003). This could, indeed, be an important path to follow for future research. Based on the achieved outcomes, these could be presented to stakeholders and adjusted to the socio-ecological needs of the region, enhancing this way the multi-level governance of natural resources.

MCA is mainly used in situations where a broad range of ecological services in a multidimensional and community-based watershed approach has to be evaluated (Prato 1999), which is essentially required for the WFD implementation. MCA can be regarded as a complement to the economic approaches, explicitly dealing with multiple criteria but avoiding the need to attribute a monetary value to all environmental factors. In this sense, the outcomes from this study can provide some insights to the economic analysis when examining the possible trade-offs and synergies between criteria/objectives aimed by decision-makers or stakeholders. The MULINO application to the Mondego Estuary can be regarded as a helpful tool for water authorities to choose the programme of measures more adequate within a river basin.

Although further investigation is still necessary, this analysis allowed the team to provide answers to some debatable issues:

\section{MULINO and DPSIR: which links?}

The DPSIR framework can be used during discussions among stakeholders but does not necessarily provide detailed enough information on the magnitude and significance of the 'state change' needed for management purposes. A next step may be the quantification of DPSIR-factors and put together in a model describing the cause-effect relationship between ecological and socio-economic systems (de Jonge et al. 2012). MULINO tries to answer this need, using the DPSIR framework to accomplish the water resource planning and decision process set by the WFD.

The DPSIR framework was designed to support decision-making processes through the introduction of the catchment structural system, where the cause-effect chains were formalised and modelled to simulate the effects of proposed management actions (Mysiak et al. 2005). This adaption aims to overcome some problems of the DPSIR framework (e.g., absence of an explicit stakeholder role) (Pinto et al. 2013a).

Despite the efforts, estimating cause-effect relations means constructing a simplified representation of the complex and overlapping relationships occurring at the catchment level (both temporal and spatial), which can influence the final decisions (Mysiak et al. 2005; de Jonge et al. 2012; Pinto et al. 2013a,b). In fact, there are no linear relationships among drivers, impacts, and status; the interactions among them are complex and at least cumulative (Pinto et al. 2013a). In addition, the identification of the driving forces, pressure and state indicators is not always straightforward, since the same indicator may be considered as a driving force or a pressure, or even confounded between a pressure and a state characteristic. For example, nutrient concentrations due to agriculture may be considered as a pressure (emissions to the water column), while they are also used to establish current water conditions (following, for example, EEA guidelines; EEA 1999).

\section{MULINO and the WFD economic requirements: which links?}

The distribution of the welfare gains/losses in society, together with existing policy measures and networks will influence policy responses (de Jonge et al. 2012). Through MCA implementation, the nature of decisions arising during the WFD implementation can be estimated and the choice of an appropriate decision support methodology for a specific 
decision can be facilitated (Mysiak et al. 2005). MULINO allows the inclusion of economic decision methods, e.g., cost-effectiveness analysis (CEA) and cost-benefit analysis (CBA), which are foreseen by the WFD for specific situations (e.g., Brouwer et al. 2009). These economic analyses seek to evaluate the social welfare gains/losses from an economic efficiency perspective, tempered by any distributional equity considerations, other precautionary environmental standards and regional economic constraints (most often focussed on local employment and economic multiplier impacts which can result in cultural and community losses or gains, e.g., closure or restrictions on fisheries) (de Jonge et al. 2012).

CEA is a decision-oriented tool designed to compare the costs and effectiveness of alternative measures (Levin and McEwan 2000), choosing the least expensive alternative that guarantees the goals' achievement (Mysiak et al. 2005). The benefits need not be expressed monetarily. When the expected costs of measures are disproportionately high, the WFD recommends CBA application (Mysiak et al. 2005). Unlike CEA, CBA requires the benefits or positive impacts of measures to be expressed in monetary terms as well (Levin and McEwan 2000).

MCA is mainly used in situations where a broad range of ecological services in a multidimensional and community-based watershed approach has to be evaluated (Prato 1999), which is essentially what is to be anticipated during the WFD implementation. MCA can be regarded as a complement to the economic approaches, explicitly dealing with multiple criteria but avoiding the need to attribute a monetary value to all environmental factors. The outcomes from this study can provide some insights to the economic analysis when examining the possible trade-offs and synergies between criteria/objectives aimed by each decision-makers or stakeholders. MCA, more specifically the MULINO application to the Mondego Estuary, can be regarded as a helpful tool for water authorities to choose the more adequate programme of measures for a river basin.

Moreover, the inclusion of the ecosystem services approach (ESA) should be useful to make the diverse impacts of measures more transparent, since the RBMP approach was quite opaque. It should be noted that, in spite of WFD recommendations for the inclusion of economic instruments in the programme of measures, those listed here do not include such instruments because there is insufficient data on water demand for the different sectors, which means that it would be hard to evaluate the cost (in terms of welfare burden) and the effectiveness of possible economic measures such as tariff increases, changes in the Water Resource Charge or other charges.

\section{General Conclusions}

This research showed that MCA tools, more specifically the MULINO software, may offer a scientifically sound analytical framework for environmental management, in general, and specifically for selecting ideal catchment management alternatives. Nevertheless, the integration of these outcomes into the WFD public participation and economics requirements may still require further research and analysis.

The main advantages resulting from the MULINO application to the Mondego Estuary case-study were:

- $\quad$ to allow the use of all the available data, both quantitative and qualitative, integrating different kinds of information; 
- to simplify and explain the several objectives elements inherent to a decision (data, criteria, and alternatives), placing the entire decision process into a single matrix;

- to provide a tool to organize complex decisions, making them more accessible to a rational decision process;

- $\quad$ to produce results that are reproducible and organized.

The next steps should be:

- $\quad$ to discuss the possibility to integrate the MULINO outcomes within the WFD economic articles; and

- $\quad$ to discuss the outcomes with decision-makers (e.g., inclusion on the RBMP).

In conclusion, the MULINO software can be an effective tool to evaluate several improvement alternatives during a decision-making process, while promoting the effective participation of stakeholders during the planning process.

Acknowledgements The present work was prepared within the scope of the research projects ESAWADI (ERA-IWRM/0001/2009) and DESAFIO (FP7-SSH-2012-2). Additionally it benefited from one grant attributed by FCT (SFRH/BPD/90675/2012). Catarina Roseta-Palma acknowledges support through FCT Strategic Project, PEst-OE/EGE/UI0315. An initial version of this paper was presented at the 8th International Conference of the EWRA in Porto, Portugal, June 26-29, 2013.

\section{References}

Borja Á, Galparsoro I, Solaun O, Muxika I, Tello EM, Uriarte A, Valencia V (2006) The European Water Framework Directive and the DPSIR, a methodological approach to assess the risk of failing to achieve good ecological status. Estuar Coast Shelf Sci 66:84-96. doi:10.1016/j.ecss.2005.07.021

Brouwer R (2008) The potential role of stated preference methods in the Water Framework Directive to assess disproportionate costs. J Environ Planning Manage 51:597-614

Brouwer R, Oosterhuis FH, Ansink JH, Barton DN, Lienhoop N (2009) POLICYMIX WP 4: Guidelines for estimating costs and benefits of policy instruments for biodiversity conservation. POLICYMIX Technical Brief 50pp

Bruins RJF, Heberling MT (2005) Economics and Ecological Risk Assessment. Applications to Watershed Management. CRC Press, 446pp

de Jonge VN, Pinto R, Turner K (2012) Integrating ecological, economic and social aspects to generate useful management information under the EU Directives' 'Ecosystem Approach'. Ocean Coast Manage 68:169188

EC (2000) Directive 2000/60/EC of European Parliament and of the Council of 23 October 2000 establishing a framework for community action in the field of water policy. Off. J. Eur. Comm., L327, 22/12/200:00010073

EEA (1999) Nutrients in European Ecosystems. Environmental Assessment Report No. 4. European Environmental Agency, Copenhagen, $155 \mathrm{pp}$

Flindt MR, Kamp-Nielsen L, Marques JC, Pardal MA, Bocci M, Bendoricchio G, Salomonsen J, Nielsen SN, Jørgensen SE (1997) Description of the three shallow estuaries: Mondego River (Portugal), Roskilde Fjord (Denmark) and the lagoon of Venice (Italy). Ecol Model 102:17-31

Giupponi C (2007) Decision support systems for implementing the European water framework directive: the MULINO approach. Environ Model Softw 22(2):248-258

Giupponi C, Cogan V (2000) Supporting integrated decision-making for sustainable management of water resources in European catchments. Contract no. EVK1-2000-00082 
Hajkowicz S, Higgins A, Miller C, Marinoni O (2009) Is getting a conservation model used more important than getting it accurate? Biol Conserv 142:699-700

Hermann BG, Kroeze C, Jawjit W (2007) Assessing environmental performance by combining life cycle assessment, multi-criteria analysis and environmental performance indicators. J Clean Prod 15:1787-1796

Kiker GA, Bridges TS, Varghese A, Seager TP, Linkov I (2005) Application of multicriteria decision analysis in environmental decision making. Integr Environ Assess Manag 1(2):95-108

La Jeunesse I, Rounsevell M, Vanclooster M (2003) Delivering a decision support system tool to a river contract: a way to implement the participatory approach principle at the catchment scale? Phys Chem Earth 28:547554

Levin HM, McEwan PJ (2000) Cost-effectiveness analysis as an evaluation tool. International Handbook of Educational Evaluation 42pp

Linkov I, Satterstrom FK, Kiker G, Batchelor C, Bridges T, Ferguson E (2006) From comparative risk assessment to multi-criteria decision analysis and adaptive management: Recent developments and applications. Environ Int 32:1072-1093

Malczewski J (1999) GIS and Multicriteria Decision Analysis. John Wiley \& Sons, Inc, New York

Marques JC, Maranhão P, Pardal MA (1993) Human impact assessment on the subtidal macrobenthic community structure in the Mondego estuary (Western Portugal). Estuar Coast Shelf Sci 37:403-419

Marques JC, Nielsen SN, Pardal MA, Jørgensen SE (2003) Impact of eutrophication and river management within a framework of ecosystem theories. Ecol Model 166(1-2):147-168

Martins I, Pardal MA, Lillebø AI, Flindt MR, Marques JC (2001) Hydrodynamics as a major factor controlling the occurrence of green macroalgal blooms in a eutrophic estuary: a case study on the influence of precipitation and river management. Estuar Coast Shelf Sci 52:165-177

Morris J (2007) Water Policy, Economics and the EU Water Framework Directive. In Pretty J, Ball AS, Benton T, Guivant J, Lee DR, Orr D, Pfeffer MJ, Ward H The SAGE Handbook of Environment and Society. SAGE Publications Ltd (Chapter 13)

Mysiak J, Giupponi C, Fassio A (2002) Decision Support for Water Resource Management: An Application Example of the MULINO DSS. Conference IEMSS 2002-Integrated Assessment and Decision Support, IEMSS, Lugano, pp. 138-143.

Mysiak J, Giupponi C, Rosato P (2005) Towards the development of a decision support system for water resource management. Environ Model Softw 20:203-214

Pavlikakis GE, Tsihrintzis VA (2003) A Quantitative Model for Accounting Human Opinion, Preferences and Perceptions in Ecosystem Management. J Environ Manage 68(2):193-205

Pinto R, Patrício J, Neto JM, Salas F, Marques JC (2010) Assessing estuarine quality under the ecosystem services scope: ecological and socio-economic aspects. Ecol Complex 7:389-402

Pinto R, de Jonge VN, Neto JM, Domingos T, Marques JC, Patrício J (2013a) Towards a DPSIR driven integration of ecological value, water uses and ecosystem services for estuarine systems. Ocean Coast Manage 72:64-79

Pinto R, de Jonge VN, Chainho P, Costa JL, Marques JC, Patrício J (2013b) Temporal stability in estuarine systems: implications for ecosystem services provision. Ecol Ind 24:246-253

Pinto R, de Jonge VN, Marques JC (2014) Linking biodiversity indicators, ecosystem functioning, provision of services and human well-being in estuarine systems: Application of a conceptual framework. Ecol Ind 36: $644-655$

Prato T (1999) Multiple attribute decision analysis for ecosystem management. Ecol Econ 30(2):207-222

Rodrigues JC (2002) Gestão de empreendimentos: avaliação e gestão em processos de engenharia (2nd edition) Gráfica EDILIBER-Coimbra

Ross S, Westerfield R, Jordan B (2013) Fundamentals of Corporate Finance. 10th ed McGrawHill.

Salas F, Marcos C, Neto JM, Patrício J, Perez-Ruzafa A, Marques JC (2006) User-friendly guide for using benthic ecological indicators in coastal and marine quality assessment. Ocean Coast Manage 49:308-331

Seppelt R, Dormann CF, Eppink FV, Lautenbach S, Schmidt S (2011) A quantitative review of ecosystem service studies: approaches, shortcomings and the road ahead. J Applied Ecol 48:630-636

Stratford CJ, Acreman MC, Rees HG (2011) A simple method for assessing the vulnerability of wetland ecosystem services. Hydrol Sci J 56(8):1485-1500

Villa F, Tunesi L, Agardy T (2002) Zoning Marine Protected Areas through Spatial Multi-Criteria Analysis: the Case of the Asinara Island National Marine Reserve of Italy. Conserv Biol 16(2):515-526

Vitousek PM, Mooney HA, Lubchenco J, Melillo JM (1997) Human domination of earth ecosystems. Science 277:494-499 